\title{
Successful management of ARDS with bronchopleural fistula secondary to miliary tuberculosis using a conventional ventilator
}

\author{
P. Malhotra, R. Agarwal, D. Gupta, A.N. Aggarwal
}

ABSTRACT: Successful management of ARDS with bronchopleural fistula secondary to miliary tuberculosis using a conventional ventilator. P. Malhotra, R. Agarwal, D. Gupta, A.N. Aggarwal.

Most institutions in India and other developing countries do not have facilities for high frequency ventilation in adults. We report the successful management of a case of ARDS with bronchopleural fistula secondary to miliary tuberculosis using a conventional ventilator and early empiric anti-tubercular therapy.

Monaldi Arch Chest Dis 2005; 63: 3, 163-165.

Keywords: Miliary tuberculosis, ARDS, bronchopleural fistula, conventional ventilator.

Department of Pulmonary and Critical Care Medicine; Postgraduate Institute of Medical Education and Research, Chandigarh, India. Correspondence: Dr.Puneet Malhotra; Dept. of Pulmonary Medicine; PGIMER; Chandigarh-160012, India; e-mail: dranshupuneet@yahoo.co.in

\section{Introduction}

Bronchopleural fistulas (BPF) continue to present a formidable management and therapeutic challenge to pulmonolgists especially when they occur in the setting of ARDS. It is generally believed that high-frequency ventilation in these patients is superior to conventional modes of ventilation in achieving gas exchange goals and minimizing air-leak. However, this modality of ventilation is not available for adults in most centres in India and other developing countries. We describe the successful management of a 21-year-old female presenting with ARDS and BPF secondary to pulmonary tuberculosis using a conventional ventilator.

\section{Case Report}

A 21 year old previously healthy female presented to the Emergency Department with a 2week history of fever and non-productive cough followed by progressive dyspnea for 5 days prior to admission. Physical examination revealed marked tachypnea $(\mathrm{RR}=44 / \mathrm{min})$, pallor, mild hepatosplenomegaly and bibasal fine inspiratory crackles. There were bilateral extensive alveolar as well as fine nodular infiltrates on Chest-X-ray (CXR) (figure 1). Arterial blood gases revealed severe type 1 respiratory failure $\left(\mathrm{PaO}_{2} 40 \mathrm{~mm} \mathrm{Hg}\right.$, $\mathrm{PaCO}_{2} 25 \mathrm{mmHg}, \mathrm{HCO}_{3} 19 \mathrm{mEq} / \mathrm{L} \mathrm{pH} 7.47 \mathrm{SaO}_{2}$ $82 \%)$. Complete blood counts, renal and liver function tests were within normal limits.
Broad-spectrum intravenous antibiotics (cefotaxime and azithromycin) and high flow oxygen through a ventimask $\left(\mathrm{FiO}_{2} 0.5\right)$ were administered with no significant improvement in either the clinical condition or blood gases over the next 24 hours. The patient was shifted to the Respiratory Intensive Care Unit (RICU) where she developed a spontaneous left sided pneumothorax (volume $\approx$ $30 \%$ of hemithorax) on day two of admission. A 28 French chest tube was inserted in the $3^{\text {rd }}$ intercostal space and subsequent CXRs revealed that the lung had fully expanded even though an airleak persisted. Her clinical condition worsened and she was electively intubated and put on an assist control mode of mechanical ventilation (Hamilton Amadeus FT ventilator) with initial settings of tidal volume $300 \mathrm{ml}(6 \mathrm{ml} / \mathrm{kg}$ body weight), rate 20/min, peak insp flow (PIF) 32 $\mathrm{L} / \mathrm{min}, \mathrm{FiO}_{2} 1.0$ and PEEP $10 \mathrm{~cm} \mathrm{H}_{2} \mathrm{O}$. At these settings, her peak, plateau and mean airway pressures were 27, 23 and $12 \mathrm{~cm}$ water respectively. Excessive bubbling was noticed in the underwater seal bag and fistula leak per breath (estimated by subtracting the exhaled tidal volume from the inspiratory tidal volume - both readings being available on the Hamilton Amadeus FT ventilator) was $90 \mathrm{ml}$ or $1.8 \mathrm{~L} / \mathrm{min}$. At this point ABG was as follows: $\mathrm{PaO}_{2} 55 \mathrm{~mm} \mathrm{Hg}, \mathrm{PaCO}_{2} 47 \mathrm{mmHg}, \mathrm{HCO}_{3}$ $25 \mathrm{mEq} / \mathrm{L} \mathrm{pH} \mathrm{7.37,} \mathrm{SaO}_{2} 86 \%$. The level of applied PEEP was increased gradually to $16 \mathrm{~cm}$ water titrating to keep plateau pressure below $30 \mathrm{~cm}$. Since the fistula leak per breath continued to be high $(140 \mathrm{ml}$ or $3.5 \mathrm{~L} / \mathrm{min})$, it was felt that chang- 


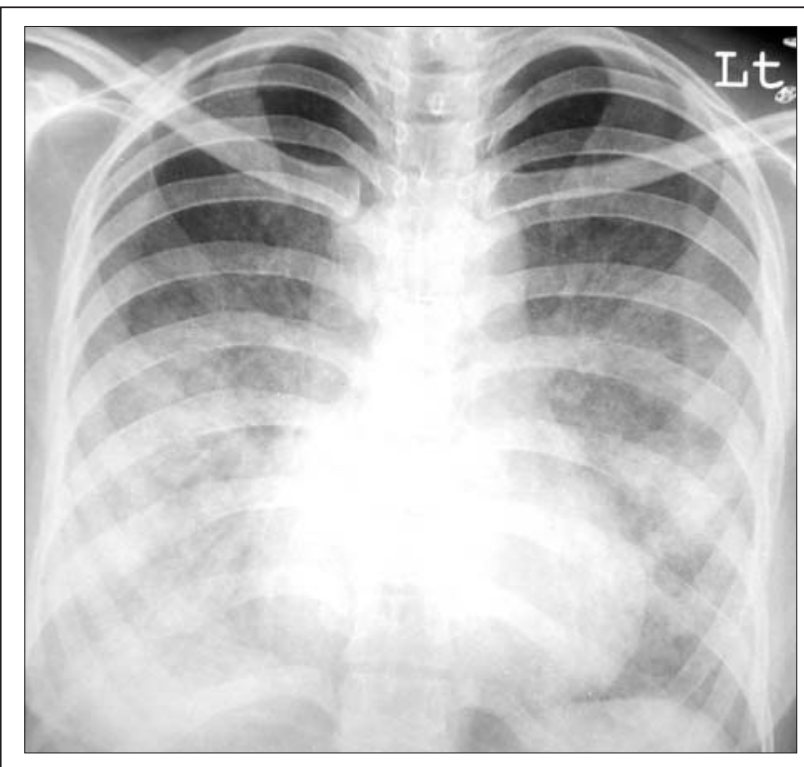

Fig. 1 - Chest X-ray demonstrates bilateral extensive alveolar and fine nodular infiltrates predominantly involving the lower lung zones.

ing the ventilator strategy to decrease airway pressures and therefore fistula flow would further improve gas exchange. Tidal volume was decreased step-wise over the next 30 minutes from $300 \mathrm{ml}$ to $100 \mathrm{ml}$ while respiratory rate was increased from 20 to $60 / \mathrm{min}$. This resulted in significant reductions in peak, plateau and mean airway pressures and hence decrease in fistula leak per breath (table 1). However the patient's saturation by oximetry dropped to $78 \%$ and an ABG analysis revealed severe hypoxemia and respiratory acidosis $\left(\mathrm{PaO}_{2} 44\right.$ $\mathrm{mm} \mathrm{Hg}, \mathrm{PaCO}_{2} 71 \mathrm{mmHg}, \mathrm{HCO}_{3} 27 \mathrm{mEq} / \mathrm{L} \mathrm{pH}$ 7.26). It therefore became clear that ventilator settings had to be modified to treat ARDS rather than the bronchopleural fistula (BPF) in order to optimise gas exchange goals and the patient was managed using a standard ventilatory strategy for ARDS subsequently.

Empirical 4 drug anti-tubercular therapy (ATT) was started on day seven after admission in view of persistent fever and lack of improvement in respiratory parameters as well as the presence of fine nodular infiltrates on CXR. Over the next ten days she became a-febrile and the requirements for PEEP and $\mathrm{FiO}_{2}$ gradually decreased. Tracheal aspirate bacterial culture was sterile and smears for AFB negative on 3 occasions. The patient was extubated uneventfully on day 22 post-admission. A transbronchial lung biopsy performed subsequently revealed caseating granulomas positive for acidfast bacilli. The patient was discharged in a satisfactory condition on ATT after povidone-iodine pleurodesis of the left pleural cavity. At the twomonth follow up there was complete clearing of the CXR and no recurrence of pneumothorax.

\section{Discussion}

In India and other developing countries, tuberculosis remains one of the most common causes of BPF [1]. Tuberculosis is also being increasingly recognised as a cause of ARDS [2-5]. Although exact figures as to what percentage of cases of ARDS are tubercular in aetiology are not available, in Southeast Asia tuberculosis accounts for $3-16 \%$ of cases of community-acquired pneumonia [6,7]. In our RICU, 185 cases $(18.8 \%)$ out of a total of 984 admissions had ARDS over an 8-year period of which tuberculosis accounted for seven (3.8\%). The pathogenetic mechanism of ARDS in patients with pulmonary tuberculosis has not been clearly elucidated. Postulated mechanisms include massive release of mycobacteria into the pulmonary circulation resulting in inflammation, obliterative endarteritis and damage of the alveolocapillary membrane [8]. Platelet aggregation in pulmonary capillaries causing endothelial injury and leukocyte activation resulting in increased vascular permeability are other hypotheses. In addition, lipoarabinomannan, a component of mycobacterial cell wall, is thought to act in a manner similar to lipopolysaccharide in bacterial sepsis to activate macrophages to release tumour necrosis factor- $\alpha$ [TNF- $\alpha]$ and interleukin- $1 \beta$ [IL-1 $\beta]$. The activation of macrophages is thought to be a key step in the causation of lung injury [9]. It is yet to be determined, whether it is the individual host immunologic responses independent of organism burden or differences in the virulence of different strains of Mycobacterium tuberculosis which are the prime factors in the development of lung injury.

The presence of a BPF in mechanically ventilated patients presents problems in achieving adequate ventilation and oxygenation while allowing repair of the BPF to occur. The fistula site provides an area of low resistance to airflow and allows the escape of a variable percentage of the delivered

Table 1. - Effects of sequential reduction of mean airway pressure by reduction of PEEP and tidal volume and compensatory increase of rate on fistula leak

\begin{tabular}{|c|c|c|c|c|c|c|c|c|}
\hline $\begin{array}{l}\text { Tidal } \\
\text { volume } \\
(\mathrm{ml})\end{array}$ & $\begin{array}{c}\text { Respiratory } \\
\text { rate/min }\end{array}$ & $\begin{array}{c}\text { Peak } \\
\text { inspiratory } \\
\text { flow }(\mathrm{L} / \mathrm{min})\end{array}$ & $\begin{array}{c}\text { PEEP } \\
\left(\mathrm{cm} \mathrm{H} \mathrm{H}_{2} \mathrm{O}\right)\end{array}$ & $\begin{array}{c}\text { Peak } \\
\text { pressure } \\
\left(\mathrm{cm} \mathrm{H} \mathrm{H}_{2} \mathrm{O}\right)\end{array}$ & $\begin{array}{c}\text { Plateau } \\
\text { pressure } \\
\left(\mathrm{cm} \mathrm{H} \mathrm{H}_{2} \mathrm{O}\right)\end{array}$ & $\begin{array}{c}\text { Mean airway } \\
\text { pressure } \\
\left(\mathrm{cm} \mathrm{H}_{2} \mathrm{O}\right)\end{array}$ & $\begin{array}{l}\text { Leak/breath } \\
\text { (ml) }\end{array}$ & $\begin{array}{c}\text { Leak/min } \\
(\mathrm{L} / \mathrm{min})\end{array}$ \\
\hline 300 & 20 & 28 & 10 & 27 & 23 & 12 & 90 & 1.8 \\
\hline 300 & 25 & 33 & 12 & 29 & 25 & 13 & 110 & 2.75 \\
\hline 300 & 25 & 33 & 16 & 32 & 28 & 15 & 140 & 3.5 \\
\hline 200 & 35 & 26 & 10 & 21 & 19 & 9 & 55 & 1.375 \\
\hline 150 & 45 & 24 & 6 & 19 & 16 & 8 & 35 & 1.575 \\
\hline 100 & 60 & 20 & 5 & 16 & 13 & 6 & 18 & 1.08 \\
\hline
\end{tabular}


tidal volume thus compromising ventilation and delaying healing of the fistula [10].

It is imperative for the clinician to decide while ventilating patients of ARDS with coexisting BPF whether gas exchange and alveolar ventilation are being compromised predominantly by alveolar filling due to ARDS, or by airleak due to the BPF. In our case it was ARDS which was mainly responsible for hypoxemia, since employing a strategy of very low tidal volumes and high rates actually worsened hypoxemia and respiratory acidosis even though air leak decreased significantly. In contrast, increasing PEEP from 5 to 16 $\mathrm{cm}$ water increased the volume of airleak/breath but also improved gas exchange parameters.

High frequency ventilation (HFV) is generally considered to be superior to conventional positive pressure ventilation in patients with BPF, since the lower airway pressures with the former mode can reduce fistula leak and loss of effective tidal volume [11]. However the use of HFV in patients with BPF and concomitant parenchymal lung disease such as ARDS is controversial. The variable success reported with HFV in patients with ARDS and BPF may be related to differences in study design, in the degree of parenchymal involvement and in the location and size of the BPF. Survival is poor in this group of patients although this has been attributed to the severity of the underlying disease rather than the mode of ventilation [12-14]. The difference in success using HFV in patients with BPF and normal lung parenchyma versus those with an abnormal parenchyma (ARDS) can be explained keeping in mind that impedance to flow through an airway depends on 3 factors: airway resistance, compliance of the lung and the frequency of ventilation. HFV increases airway impedance and reduces the importance of lung compliance on distribution of airflow. Therefore in the setting of normal lung compliance and a BPF having infinite compliance, HFV redistributes airflow to lung parenchyma by bypassing the airleak. On the other hand patients with ARDS have poor lung compliance and HFV is less effective in decreasing air leak because compliance becomes a greater determinant of airflow than impedance [15].

An additional factor responsible for the poor success of HFV in BPF with ARDS is the more peripheral location of fistulas in patients with ARDS compared to those with a normal lung parenchyma. According to Bernoulli's equation, during HFV lateral airway pressure is increased to a greater extent in peripheral airways than more proximal ones, hence air leak is more in the peripheral BPFs of patients with ARDS during HFV [16].

This case therefore illustrates that patients with BPF arising in the setting of ARDS can be managed effectively using a conventional ventilator. In patients with ARDS of obscure etiology in regions with a high prevalence of tuberculosis, antitubercular therapy may be started empirically and the diagnosis actively pursued. Early diagnosis and specific therapy may improve the outcome of this uncommon but treatable cause of ARDS.

\section{References}

1. Kumar A, Dilip D, Chandra A. Surgery for pleuropulmonary tuberculosis. In: Sharma SK, ed. Tuberculosis 1st ed. 2001. New Delhi: Jaypee Brothers Medical Publishers; pp 514-529.

2. Sharma SK, Mohan A, Pande JN, Prasad KL, Gupta AK, Khilnani GC. Clinical profile, laboratory characteristics and outcome in miliary tuberculosis. $Q \mathrm{~J} \mathrm{Med}$ 1995; 88: 29-37.

3. Jindal SK, Aggarwal AN, Gupta. D. Adult respiratory distress syndrome in the tropics. Clin Chest Med 2002; 23: 445-455.

4. Kim JY, Park YB, Kim YS, et al. Miliary tuberculosis and acute respiratory distress syndrome. Int $J$ Tuberc Lung Dis 2003; 7: 359-364

5. Mohan A, Sharma SK, Pande JN. Acute respiratory distress syndrome (ARDS) in miliary tuberculosis: a twelve-year experience. Indian J Chest Dis Allied Sci 1996; 38: 157-162.

6. Kobashi Y, Okimoto N, Matsushima T, Soejima R. Clinical analysis of community-acquired pneumonia in the elderly. Intern Med 2001; 40: 703-7.

7. Tan YK, Khoo KL, Chin SP, Ong YY. Aetiology and outcome of severe community-acquired pneumonia in Singapore. Eur Respir J 1998; 12: 113-5.

8. Piqureas AR, Marruecos L, Artigas A, Rodriguez C. Miliary tuberculosis and adult respiratory distress syndrome. Intensive Care Med 1987; 13: 175-182.

9. Zhang YM, Doerfler TC, Lee B, Guillemin B, Rom WN. Mechanisms of stimulation of interleukin- $1 \beta$ and tumour necrosis factor- $\alpha$ by Mycobacterium tuberculosis components. J Clin Invest 1993; 91: 2076-2083.

10. Baumann MH, Sahn SA. Medical management and therapy of brochopleural fistulas in the mechanically ventilated patient. Chest 1990; 97: 721-728.

11. Carlon GC, Kahn RC, Howland WS, Ray C, Turnbull AD. Clinical experience with high frequency jet ventilation. Crit Care Med 1981; 9: 1-6.

12. Turnbull AD, Carlon GC, Howland WS, Beattie EJ. High-frequency jet ventilation in major airway or pulmonary disruption. Ann Thorac Surg 1981; 32: 468-474.

13. Albeda SM, Hansen-Flaschen JH, Taylor E, Lanken PN, Wollman H. Evaluation of high-frequency jet ventilation in patients with bronchopleural fistula by quantitation of the airleak. Anaesthesiology 1985; 63: 551-554.

14. Carlon GC, Ray C, Pierri MK, Groeger J, Howland WS. High-frequency jet ventilation: theoretical considerations and clinical observations. Chest 1982; 81: 350-354.

15. Bishop MJ, Benson MS, Sato P, Pierson DJ. Comparison of high-frequency jet ventilation with conventional mechanical ventilation for bronchopleural fistula. Anaesth Analg 1987; 66: 933-838.

16. Mayers I, Mink JT. High-frequency oscillatory ventilation of a canine bronchopleural fistula. Crit Care Med 1989; 17: 58-62. 